\title{
Mechanism by which high-dose aspirin improves glucose metabolism in type 2 diabetes
}

\author{
Ripudaman S. Hundal, ${ }^{1}$ Kitt F. Petersen, ${ }^{1}$ Adam B. Mayerson, ${ }^{1}$ Pritpal S. Randhawa,${ }^{1}$ \\ Silvio Inzucchi, ${ }^{1}$ Steven E. Shoelson, ${ }^{2}$ and Gerald I. Shulman ${ }^{1,3,4}$ \\ ${ }^{1}$ Department of Internal Medicine, Yale University School of Medicine, New Haven, Connecticut, USA \\ 2Joslin Diabetes Center and the Department of Medicine, Harvard Medical School, Boston, Massachusetts, USA \\ ${ }^{3}$ Department of Cellular and Molecular Physiology, Yale University School of Medicine, New Haven, Connecticut, USA \\ ${ }^{4}$ Howard Hughes Medical Institute, Yale University School of Medicine, New Haven, Connecticut, USA \\ Address correspondence to: Gerald I. Shulman, Howard Hughes Medical Institute, \\ Yale University School of Medicine, Boyer Center for Molecular Medicine, 295 Congress Avenue, \\ Boyer Center for Molecular Medicine 254C, New Haven, Connecticut 06536-8012, USA. \\ Phone: (203) 785-5447; Fax: (203) 737-4059; E-mail: gerald.shulman@yale.edu.
}

Received for publication January 2, 2002, and accepted in revised form April 3, 2002.

Recent studies have implicated fatty acid-dependent activation of the serine kinase IKK $\beta$, which plays a key role in tissue inflammation, in the pathogenesis of insulin resistance. High doses of salicylates have recently been shown to inhibit IKK $\beta$ activity and might therefore ameliorate insulin resistance and improve glucose tolerance in patients with type 2 diabetes. To test this hypothesis, we studied nine type 2 diabetic subjects before and after 2 weeks of treatment with aspirin $(\sim 7 \mathrm{~g} / \mathrm{d})$. Subjects underwent mixed-meal tolerance tests and hyperinsulinemic-euglycemic clamps with $\left[6,6-{ }^{2} \mathrm{H}_{2}\right] \mathrm{glu}$ cose to assess glucose turnover before and after treatment. High-dose aspirin treatment resulted in a $\sim 25 \%$ reduction in fasting plasma glucose, associated with a $\sim 15 \%$ reduction in total cholesterol and C-reactive protein, a $\sim 50 \%$ reduction in triglycerides, and a $\sim 30 \%$ reduction in insulin clearance, despite no change in body weight. During a mixed-meal tolerance test, the areas under the curve for plasma glucose and fatty acid levels decreased by $\sim 20 \%$ and $\sim 50 \%$, respectively. Aspirin treatment also resulted in a $\sim 20 \%$ reduction in basal rates of hepatic glucose production and a $\sim 20 \%$ improvement in insulin-stimulated peripheral glucose uptake under matched plasma insulin concentrations during the clamp. In conclusion, these data support the hypothesis that $\operatorname{IKK} \beta$ represents a new target for treating type 2 diabetes mellitus.

J. Clin. Invest. 109:1321-1326 (2002). doi:10.1172/JCI200214955.

\section{Introduction}

Insulin resistance is a primary factor in the development of type 2 diabetes, and recent studies have implicated fatty acid activation of a serine/threonine kinase cascade in the pathogenesis of insulin resistance $(1-7)$. Recently Yuan et al. hypothesized that IKK $\beta$ is a key downstream mediator in this process and demonstrated that high doses of salicylates, which inhibit IKK $\beta$ activity (8), reversed hyperglycemia, hyperinsulinemia, and dyslipidemia in obese rodents by sensitizing insulin signaling (9). Evidence that these effects were mediated by salicylate inhibition of IKK $\beta$ activity, as opposed to inhibition of cyclooxygenases, was obtained by demonstrating that heterozygous deletion of IKK $\beta$ protected mice against the development of insulin resistance during high-fat feeding (9) or lipid infusion (10).

However, the effects of aspirin in patients with type 2 diabetes are less clear. While early studies suggested a salutary effect of aspirin on glucose metabolism in diabetic patients (11-16), more recent clinical trials have demonstrated a detrimental effect of aspirin therapy on insulin sensitivity (17-19). Important differences between these studies included lower aspirin dosages ( $<3 \mathrm{~g} / \mathrm{d}$ ) and therapeutic duration (a few days) in the more recent studies than in the earlier studies (6-9 g/d for 1-3 weeks). In view of the recent rodent data demonstrating a potentially important role of IKK $\beta$ in mediating insulin resistance and the ability of high-dose salicylate to inhibit IKK $\beta$ activity, we decided to examine this hypothesis in patients with type 2 diabetes. We measured basal and insulin-stimulated rates of whole-body glucose metabolism before and after high-dose aspirin therapy $(\sim 7 \mathrm{~g} / \mathrm{d})$ using hyperinsulinemic-euglycemic clamps in combination with indirect calorimetry and $\left[6,6-{ }^{2} \mathrm{H}_{2}\right]$ glucose turnover measurements. In addition, mixed-meal tolerance testing was done before, during, and after the aspirin treatment.

\section{Methods}

Study subjects. Nine subjects with type 2 diabetes (six men and three women, age $48 \pm 4$, weight $108 \pm 7 \mathrm{~kg}$, body surface area $2.2 \pm 0.1 \mathrm{~m}^{2}$, body mass index $37 \pm 3 \mathrm{~kg} / \mathrm{m}^{2}$ ) were studied before and after 2 weeks of treatment with aspirin. All the patients were initially screened to rule out any other systemic disease and any biochemical evidence of abnormal renal or hepatic functions. Patients 
with a history of alcohol abuse, symptomatic coronary heart disease, stroke, current use of insulin for glycemic control, significant hepatic enzyme elevation (more than twice the upper limit of normal), serum creatinine greater than $1.5 \mathrm{mg} / \mathrm{dl}$, history of ketoacidosis or current metabolic acidosis, history of gastric ulcer, dyspepsia, upper or lower gastrointestinal bleed, history of allergy to aspirin, or bleeding diathesis, or currently on oral anticoagulants, were excluded from the study. Women who were pregnant, lactating, or of childbearing potential and not using a barrier or hormonal method of contraception were also excluded from the study. The subjects were asked to stop their antidiabetic medications 1-2 weeks before the study period. Two subjects were diet-controlled and taking no antidiabetic medications, whereas others were on either a sulfonylurea and/or metformin. Given the relatively short biological half-lives of sulfonylurea and metformin compared with thiazolidinediones, it is likely that there were no residual effects of these compounds on any of the base-line parameters. Furthermore any residual effects of these agents would lead to an underestimation of the effect of high-dose aspirin on glucose metabolism. For 3 days prior to each inpatient study, the subjects were given a diet containing $35 \mathrm{kcal} / \mathrm{kg}$ body weight, consisting of $60 \%$ carbohydrate, $20 \%$ fat, and $20 \%$ protein, prepared by the Yale/New Haven Hospital General Clinical Research Center (GCRC) metabolic kitchen, and asked to abstain from alcohol, caffeine, and exercise, except for normal daily activities. The same diet was continued during their stay in the GCRC. The protocol was reviewed and approved by the Yale University Human Investigation Committee. Informed written consent was obtained from each subject.

Study design. Subjects were screened at the outpatient facilities of the GCRC, including physical examination, urine analysis, and a check of routine chemistries, fasting lipid panel, cell blood count, prothrombin time/partial thromboplastin time, serum glutamic oxaloacetic transaminase, alkaline phosphatase, and $\beta$ human chorionic gonadotrophin for females. Stools were checked for blood by hemoccult cards. After the washout period, each subject was admitted to the GCRC at 2100 hours 1 day prior to the day of the study. Each subject was started on 200 $\mu \mathrm{g}$ misoprostol four times per day, to prevent aspirininduced gastric ulcers, 3 days before the first inpatient visit ( 5 days before the first base-line clamp study), and the misoprostol was continued for the duration of the study. After their admission, subjects underwent a 24-hour urine collection for assessing urine creatinine and nitrogen excretion.

Mixed-meal tolerance test. After an overnight fast, a mixed-meal tolerance test was performed. At 0730 hours, a catheter was placed in the antecubital vein for blood collection. After obtaining fasting blood samples for plasma glucose, insulin, fatty acids, and $\mathrm{C}$-peptide concentrations, the subjects ingested a liquid meal consisting of $33 \%$ of their total caloric requirement ( $240 \mathrm{kcal} / 8$ ounces, $55 \%$ carbohydrate) at 0800 hours. Blood samples were then obtained periodically every half hour for the next 5 hours for plasma concentrations of glucose, insulin, C-peptide, and fatty acids.

Hyperinsulinemic-englycemic clamp study. A hyperinsulinemic-euglycemic clamp (20) was performed in the morning following an overnight fast. Two indwelling catheters were placed at 0400 hours: one for administration of insulin, glucose, and $\mathrm{K}^{+}$was inserted into an antecubital vein, and a second for blood drawing was placed in a retrograde direction into a hand vein. The hand was kept warm in a hot box at $70^{\circ} \mathrm{C}$ to "arterialize" the blood samples. Basal samples were drawn for determination of plasma glucose, insulin, C-peptide, fatty acids, glucagon, and lactate.

A primed $\left(181 \mathrm{mg} / \mathrm{m}^{2}\right)$ continuous infusion $(1.81$ $\mathrm{mg} / \mathrm{m}^{2} / \mathrm{min}$ ) of $\left[6,6-{ }^{2} \mathrm{H}_{2}\right]$ glucose was infused for 4 hours to assess rates of glucose production. During the last 40 minutes of this infusion, blood samples were drawn for the determination of enrichment of plasma $\left[6,6-{ }^{2} \mathrm{H}_{2}\right]$ glucose as well as plasma glucose and hormone concentrations. At 0800 hours, a twostep priming dose of insulin was administered for 10 minutes $\left(480 \mathrm{mU} / \mathrm{m}^{2} / \mathrm{min}\right.$ for 5 minutes, followed by $240 \mathrm{mU} / \mathrm{m}^{2} / \mathrm{min}$ for 5 minutes), followed immediately by a constant insulin infusion rate of 120 $\mathrm{mU} / \mathrm{m}^{2} / \mathrm{min}$ for a total of 5 hours as previously described (20). The plasma glucose concentration was monitored every 5 minutes and allowed to decrease to $100 \mathrm{mg} / \mathrm{dl}$, then maintained between 90 and $100 \mathrm{mg} / \mathrm{dl}$ throughout the study period by administration of glucose (20 g of dextrose per 100 $\mathrm{ml}$ enriched to approximately $2.5 \%$ with $\left[6,6-{ }^{2} \mathrm{H}_{2}\right]$ glucose). During the last 40 minutes of the fifth hour of the insulin infusion, blood samples were obtained every 10 minutes for measurements of plasma glucose, fatty acid, insulin, and $\left[6,6-{ }^{2} \mathrm{H}_{2}\right]$ glucose enrichment. To avoid insulin-induced hypokalemia, potassium was administered at a rate of 6 milli-equivalent/h. Indirect calorimetry was performed to determine whole-body glucose oxidation before and during the last 30 minutes of the hyperinsulinemic clamp (21).

Treatment period. Upon completion of the base-line study, subjects were started on enteric-coated aspirin $(6.2 \mathrm{~g} / \mathrm{d})$ divided in five equal doses (at 0700, 1100, 1500,1900 , and 2300 hours) for 2 weeks. Blood salicylate and electrolyte concentrations were monitored every 1-2 days, and the aspirin dose was adjusted to keep salicylate concentrations between 25 and 35 $\mathrm{mg} / \mathrm{dl}$. One week after the initiation of aspirin, patients were readmitted for mixed-meal tolerance testing. In addition, the subjects were seen as outpatients every other day during the treatment period to measure safety parameters (adverse event query, vital signs, stool guaiac) and to monitor compliance by blood salicylate level.

At the end of 2 weeks of study, subjects were readmitted to GCRC and underwent the same procedures 
Table 1

Patients' characteristics before and after aspirin treatment

\begin{tabular}{lccc}
\hline & $\begin{array}{c}\text { Base-line } \\
(n=9)\end{array}$ & $\begin{array}{c}\text { After treatment } \\
(n=9)\end{array}$ & $P$ value \\
Weight $(\mathrm{kg})$ & $108.2 \pm 7.0$ & $109.6 \pm 7.5$ & $\mathrm{NS}$ \\
Body surface area $\left(\mathrm{m}^{2}\right)$ & $2.2 \pm 0.1$ & $2.2 \pm 0.1$ & $\mathrm{NS}$ \\
Fasting plasma glucose $(\mathrm{mg} / \mathrm{dl})$ & $164 \pm 18$ & $125 \pm 14$ & $<0.0001$ \\
Creatinine clearance rate $(\mathrm{ml} / \mathrm{min})$ & $140 \pm 8$ & $123 \pm 8$ & 0.04 \\
Serum sodium $(\mathrm{mmol} / \mathrm{l})$ & $138 \pm 0.7$ & $140 \pm 0.8$ & 0.04 \\
Serum chloride $(\mathrm{mmol} / \mathrm{l})$ & $102 \pm 0.6$ & $109 \pm 1.1$ & 0.0002 \\
Serum bicarbonate $(\mathrm{mmol} / \mathrm{l})$ & $25 \pm 0.8$ & $21 \pm 1.0$ & 0.001 \\
Anion gap & $10 \pm 0.5$ & $10 \pm 0.5$ & $\mathrm{NS}$ \\
Serum cholesterol $(\mathrm{mg} / \mathrm{dl})$ & $212 \pm 16$ & $181 \pm 11$ & 0.01 \\
HDL $(\mathrm{mg} / \mathrm{dl})$ & $38 \pm 2$ & $34 \pm 1$ & 0.01 \\
LDL $($ calculated $)$ & $128 \pm 13$ & $125 \pm 12$ & $\mathrm{NS}$ \\
Triglycerides $(\mathrm{mg} / \mathrm{dl})$ & $227 \pm 29$ & $117 \pm 8$ & 0.009 \\
C-reactive protein $(\mathrm{mg} / \mathrm{dl})$ & $0.71 \pm 0.44$ & $0.59 \pm 0.44$ & 0.02 \\
$\quad$ & & &
\end{tabular}

as during the base-line period, with a mixed-meal tolerance test on the first day and then hyperinsulinemiceuglycemic clamp on the second day. At the completion of the study, the subjects were instructed to restart their antidiabetic medications.

Substrate and hormone measurements. Plasma glucose was measured at the bedside with a Beckman Instruments Inc. Glucose Analyzer II (Fullerton, California, USA). Plasma insulin and glucagons were determined by RIA (Linco Research, St. Charles, Missouri, USA), with an interassay coefficient of variation of $10.8 \%$ and an intra-assay coefficient of variation of $9.9 \%$ for insulin, and an interassay coefficient of variation of $7.4 \%$ and an intra-assay coefficient of variation of $6.9 \%$ for glucagon. Plasma C-peptide was also measured by RIA (Linco Research), with an interassay coefficient of variation of $10 \%$ and an intra-assay coefficient of variation of $7.9 \%$. Plasma fatty acid concentrations were determined using a microfluorometric method (22), and plasma lactate concentrations were measured using a lactate dehydrogenase method (23). Urine nitrogen was done at the Mayo Medical Laboratories (Rochester, Minnesota, USA). [6,6- $\left.{ }^{2} \mathrm{H}_{2}\right]$ glucose enrichment was measured by gas chromatography-mass spectrometry analysis (24).

Calculations. Rate of endogenous glucose production $(\mathrm{EGP})(\mathrm{mg} / \mathrm{kg} / \mathrm{min})=$ isotope infusion rate $\times[$ (enrichment $^{\text {infusate }} /$ enrichment plasma $\left.^{\text {- }}-1\right]$.

Glucose disposal rate $(\mathrm{Rd})(\mathrm{mg} / \mathrm{kg} / \mathrm{min})=$ endogenous glucose production during the clamp (cEGP) + glucose infusion rate (GIR). GIR is the mean rate of infusion of exogenous glucose from minutes 200-300 of the clamp period $(\mathrm{mg} / \mathrm{kg} / \mathrm{min})$. cEGP was calculated as follows: $c E G D=G I R \times\left[\right.$ enrichment $t^{\text {infusate }} /$ enrichmentplasma) - 1].

Insulin clearance rate $(\mathrm{ml} / \mathrm{min})=$ insulin infusion rate $(\mathrm{pmol} / \mathrm{min}) / \mathrm{plasma}$ insulin concentration $(\mathrm{pmol} / \mathrm{ml})$.

Statistical analysis. Data are expressed as mean \pm SE. Paired $t$ test was used to assess the differences between measurements before and after treatment. The area under the curve was used to compare different substrate and hormone profiles during the mixed-meal tolerance test and the clamp period before and after treatment.

\section{Results}

Base-line characteristics of diabetic subjects, before and after 2 weeks of treatment with aspirin, are shown in Table 1 . The average dose of aspirin was $6.77 \pm 0.34 \mathrm{~g}$, with a mean plasma salicylate level of $27.4 \pm 2.0 \mathrm{mg} / \mathrm{dl}$. There was no significant change in body weight. All the patients completed the study with no major side effects. The only minor side effects were tinnitus and mild hearing loss, which tended to decrease with continuation of the treatment and disappeared completely after the aspirin was stopped. A few subjects had transient diarrhea, flatulence, and abdominal cramps at the start of misoprostol, which disappeared as they continued the medication. Although the mean plasma bicarbonate concentrations decreased by $4 \mathrm{mM}$ following aspirin therapy,

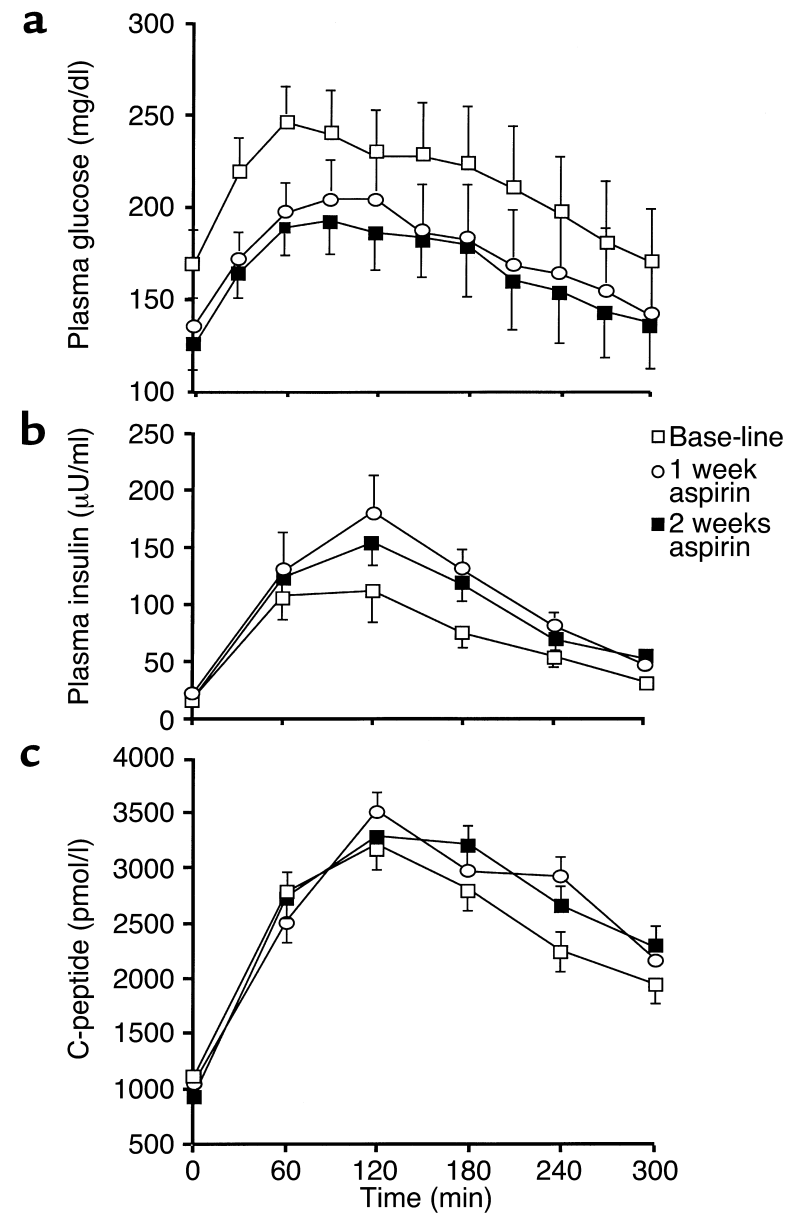

Figure 1

Mean plasma concentrations of glucose (a), insulin (b), and C-peptide (c) during mixed-meal tolerance testing. 


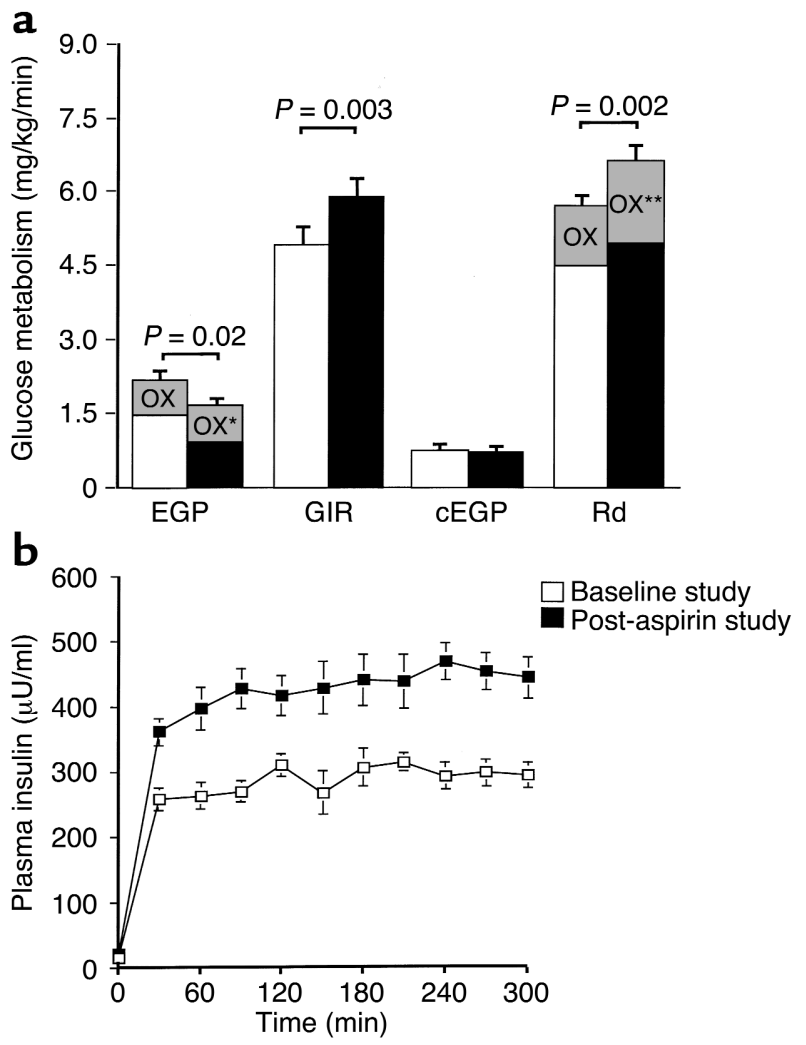

this was not felt to be clinically significant since the concentrations were still in the normal range and were unassociated with an anion gap. Liver enzymes did not change during the aspirin therapy.

Two weeks of aspirin treatment resulted in a drop of about $40 \mathrm{mg} / \mathrm{dl}$ in fasting plasma glucose concentration, and this drop was not associated with any episodes of hypoglycemia (Table 1). There was a small but significant decrease in creatinine clearance rate $(12 \%)$ that normalized following discontinuation of aspirin. There were also significant decreases in concentrations of plasma cholesterol (15\%), HDL cholesterol (10\%), triglycerides (48\%), and C-reactive protein (17\%).

Mixed-meal tolerance test. Aspirin treatment resulted in a significant decrease in plasma glucose concentrations during the mixed-meal tolerance tests $(21 \%$ decrease in area under the curve [AUC], $P=0.0001$ ); this decrease was associated with a $34 \%$ increase (AUC, $P=0.0003)$ in plasma insulin levels, but no difference in C-peptide levels (AUC, $P=0.31$ ) (Figure 1). There was no difference in fasting plasma concentrations of insulin, C-peptide, or glucagon (data not shown). Aspirin treatment also caused an approximately 50\% decrease in fasting plasma fatty acid concentration $(727 \pm 76$ vs. $379 \pm 43 \mu \mathrm{M})$ and a $52 \%$ decrease $(P=0.005)$ in AUC for the plasma fatty acids levels.

\section{Figure 3}

(a) Rates of glucose metabolism in a subgroup of six subjects for the post-aspirin and matched insulin studies. (b) Mean plasma insulin concentrations for the two studies in the same subgroup of subjects.

\section{Figure 2}

(a) Rates of glucose metabolism before and after aspirin treatment. EGP, endogenous glucose production; GIR, glucose infusion rate during the clamp; cEGP, endogenous glucose production during the clamp; Rd, glucose disposal rate during the clamp; OX, glucose oxidation rates. ${ }^{*} P=0.009,{ }^{*} P=0.003$ vs. base-line. (b) Mean plasma insulin concentrations during the hyperinsulinemiceuglycemic clamp.

Hyperinsulinemic-euglycemic clamp. Glucose production decreased by $25 \%$ after aspirin treatment ( $2.1 \pm 0.2$ vs. $1.6 \pm 0.1 \mathrm{mg} / \mathrm{kg} / \mathrm{min}$ ) (Figure 2). There was a significant $20 \%$ increase in the mean exogenous glucose infusion rate during the clamps after treatment $(4.9 \pm 0.5$ $\mathrm{mg} / \mathrm{kg} / \mathrm{min}$ before vs. $5.9 \pm 0.6 \mathrm{mg} / \mathrm{kg} / \mathrm{min}$ after treatment) and a significant $16 \%$ increase in the mean glucose disposal rate after treatment $(5.7 \pm 0.6 \mathrm{mg} / \mathrm{kg} / \mathrm{min}$ before vs. $6.6 \pm 0.6 \mathrm{mg} / \mathrm{kg} / \mathrm{min}$ after treatment). When the data were analyzed according to the mean percent changes in these values within subjects, endogenous glucose production decreased by a mean of $22 \% \pm 6 \%$ $(P=0.005)$, with a mean increase of $19 \% \pm 7 \%(P=0.02)$ in glucose disposal rates. However, it was also noted that plasma insulin levels were $47 \%$ higher during the post-aspirin clamp study than during the pre-aspirin clamp study, despite identical insulin infusion rates. Most of the difference was explained by decreased hepatic clearance rates for insulin $(928 \pm 64 \mathrm{ml} / \mathrm{min}$ before vs. $655 \pm 50 \mathrm{ml} / \mathrm{min}$ after treatment, $P<0.0001$ ), consistent with previous findings (19).

Oxidation rates. Glucose oxidation rates improved significantly following 2 weeks of aspirin therapy, under basal conditions $(0.8 \pm 0.1 \mathrm{mg} / \mathrm{kg} / \mathrm{min}$ before

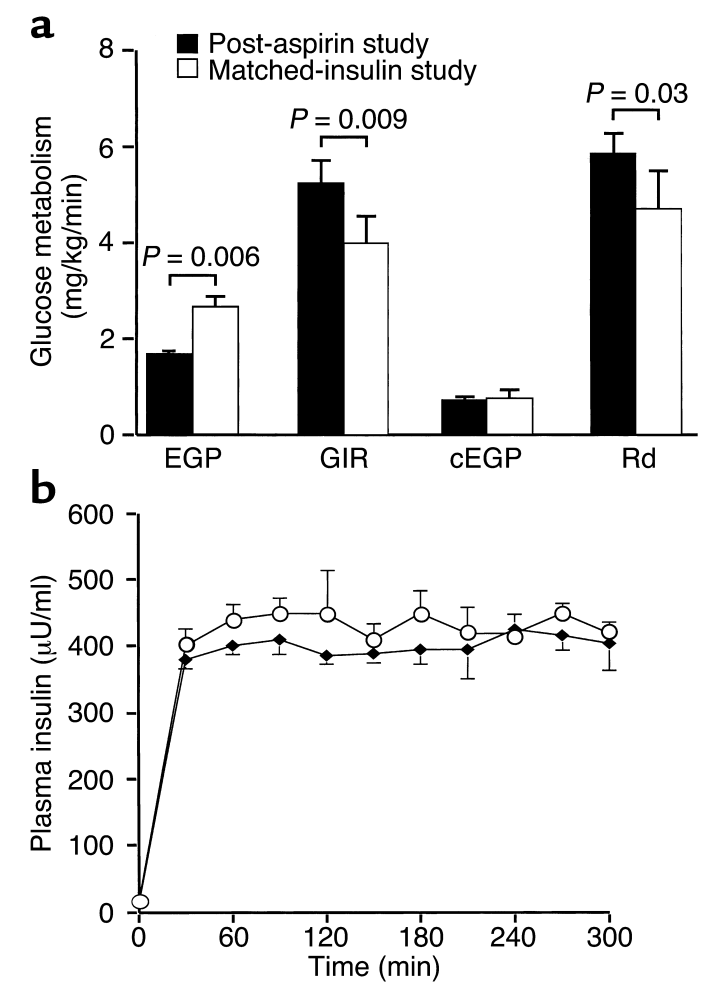


vs. $0.9 \pm 0.1 \mathrm{mg} / \mathrm{kg} / \mathrm{min}$ after treatment, $P=0.009$ ) and during the hyperinsulinemic clamp studies $(1.3 \pm 0.1 \mathrm{mg} / \mathrm{kg} / \mathrm{min}$ before vs. $1.7 \pm 0.1 \mathrm{mg} / \mathrm{kg} / \mathrm{min}$ after treatment, $P=0.003$ ) (Figure 2). Basal rates of fat oxidation were also increased following aspirin treatment $(3.1 \pm 0.2 \mathrm{mg} / \mathrm{kg} / \mathrm{min}$ before vs. $3.6 \pm 0.2$ $\mathrm{mg} / \mathrm{kg} / \mathrm{min}$ after treatment, $P<0.05)$, but insulinstimulated rates were unchanged $(1.8 \pm 0.2$ $\mathrm{mg} / \mathrm{kg} / \mathrm{min}$ before vs. $1.5 \pm 0.2 \mathrm{mg} / \mathrm{kg} / \mathrm{min}$ after aspirin treatment).

Hyperinsulinemic-englycemic clamp (matched insulin). In order to assess insulin responsiveness under similar plasma insulin concentrations, we repeated baseline hyperinsulinemic-euglycemic clamps in six subjects following discontinuation of their aspirin treatment with a higher dose of insulin (150 $\mathrm{mU} / \mathrm{m}^{2} / \mathrm{min}$ ) to match the plasma insulin concentrations achieved during the hyperinsulinemic-euglycemic clamp following aspirin treatment (Figure 3). As before, the rate of endogenous glucose production was significantly higher after washout than after aspirin treatment $(2.6 \pm 0.3$ vs. $1.6 \pm 0.1 \mathrm{mg} / \mathrm{kg} / \mathrm{min}$, $P=0.006$ ). Furthermore, despite similar plasma insulin concentrations during the clamp, aspirin treatment still resulted in a higher mean rate of exogenous glucose infusion required to maintain euglycemia during the clamp $(4.0 \pm 0.7$ vs. $5.2 \pm 0.6$ $\mathrm{mg} / \mathrm{kg} / \mathrm{min}, P=0.009)$, as well as a higher mean rate of insulin-stimulated glucose disposal ( $4.7 \pm 0.9$ vs. $5.9 \pm 0.6 \mathrm{mg} / \mathrm{kg} / \mathrm{min}, P=0.03)$, reflecting increased peripheral insulin responsiveness (Figure 3 ).

\section{Discussion}

In 1877 Ebstein (11), and again in 1901 Williamson (12), found that high doses of sodium salicylate dramatically reduced glucosuria in diabetic patients. In 1957 Reid et al. serendipitously rediscovered aspirin's effect to reduce glycosuria and blood glucose in a diabetic patient he was treating with high-dose aspirin for "acute rheumatism" (13), prompting more detailed prospective analyses. Glucose tolerance was improved by aspirin therapy in diabetic subjects (13, $15)$, and aspirin was shown to reduce insulin requirements (14). Conflicting results on the effects of aspirin in normal $(17,18)$ and diabetic subjects $(19)$ were subsequently reported.

In view of the recent rodent data demonstrating a potentially important role of IKK $\beta$ in mediating insulin resistance in obesity and the ability of highdose salicylate to inhibit $\operatorname{IKK} \beta$ activity $(9,10)$, we decided to examine whether high-dose aspirin would ameliorate insulin resistance in patients with type 2 diabetes. We found that a 2 -week trial of high-dose aspirin treatment was accompanied by significant decreases in hepatic glucose production $(22 \%)$, fasting plasma glucose (24\%), fatty acids (50\%), and triglycerides (48\%) and a 19\% increase in peripheral glucose disposal. The reductions in fasting plasma glucose concentration and glucose production are comparable to the effects of metformin in type 2 diabetic patients and occurred independently of any changes in fasting plasma insulin or C-peptide concentrations $(25,26)$. In contrast, the aspirin-induced increase in insulin-stimulated glucose uptake observed during the clamp study was associated with an approximately $47 \%$ increase in plasma insulin concentrations, which could be attributed to decreased insulin clearance. After matching these higher insulin levels during a repeat hyperinsulinemic-euglycemic clamp study, peripheral glucose uptake rates were still about $25 \%$ higher, demonstrating that highdose aspirin improves peripheral insulin sensitivity. These data are consistent with recent animal studies demonstrating that high-dose aspirin therapy protects against fat-induced insulin resistance through inhibition of IKK $\beta$ activity $(9,10)$.

Aspirin therapy also resulted in significant reductions in postprandial hyperglycemia during the mixed-meal tolerance test, a result that can likely be attributed to the combined effects of increased peripheral insulin sensitivity and higher plasma insulin concentrations. Since there was no significant difference in the plasma C-peptide concentrations during the mixed meal, this increase in plasma insulin concentration can likely be ascribed to a decrease in insulin clearance.

Aspirin therapy also resulted in significant reductions in both fasting and postprandial plasma fatty acid concentration, and such reductions can also contribute to enhanced insulin action in liver and muscle $(6,27-29)$. This result suggests that highdose aspirin may also have an insulin-sensitizing effect or a direct antilipolytic effect on adipocytes, leading to reduced rates of lipolysis and lower plasma fatty acid levels, which in turn could lead to enhanced insulin sensitivity in liver and muscle. However, recent animal studies by our group have shown that high-dose aspirin protects against insulin resistance due to raised plasma fatty acid concentrations induced by infusing intralipid along with heparin to activate lipoprotein lipase. This suggests that there is a protective effect of aspirin downstream from where it lowers plasma fatty acid concentrations (10).

In summary, high dose aspirin treatment improved both fasting and postprandial hyperglycemia in patients with type 2 diabetes, an effect that could be attributed to decreased basal rates of hepatic glucose production, enhanced peripheral insulin sensitivity, and decreased insulin clearance. In view of the potential toxicities associated with chronic high-dose aspirin, we would strongly advocate against its use for treatment of type 2 diabetes. However, these data are consistent with the hypothesis that a serine kinase cascade is involved in the pathogenesis of insulin resistance in type 2 diabetes and suggest that the IKK $\beta$ pathway may represent a new target for treating this disease. 


\section{Acknowledgments}

We are grateful to Fran Rife and the staff members of Yale/New Haven Hospital General Clinical Research Center for assistance with these studies, and James Dziura for his assistance with the statistical analysis. This work was supported by grants from the US Public Health Service (R01 DK-49230, R01 DK-51729, P30 DK-34576, K23 DK-02734, and M01 RR-00125).

1. De Fea, K., and Roth, R.A. 1997. Protein kinase C modulation of insulin receptor substrate-1 tyrosine phosphorylation requires serine 612 Biochemistry. 36:12939-12947.

2. Schmitz-Peiffer, C., et al. 1997. Alterations in the expression and cellular localization of protein kinase $\mathrm{C}$ isozymes epsilon and theta are associated with insulin resistance in skeletal muscle of the high fat fed rat. Diabetes. 46:169-178.

3. Hotamisligil, G.S., Shargill, N.S., and Spiegelman, B.M. 1993. Adipose expression of tumor necrosis factor: direct role in obesity-linked insulin resistance. Science. 259:87-91.

4. Rui, L., et al. 2001. Insulin/IGF-1 and TNF-alpha stimulate phosphorylation of IRS-1 at inhibitory Ser307 via distinct pathways. J. Clin. Invest. 107:181-189.

5. Shulman, G.I. 2000. Cellular mechanisms of insulin resistance. J. Clin Invest. 106:171-176.

6. Dresner, A., et al. 1999. Effect of free fatty acids on IRS-1 associated phosphatidylinositol 3-kinase activity. J. Clin. Invest. 103:253-259.

7. Griffin, M.E., et al. 1999. Free fatty acid-induced insulin resistance is associated with activation of protein kinase $\mathrm{C}$ and alterations in the insulin signaling cascade. Diabetes. 48:1270-1274.

8. Yin, M.J., Yamamoto, Y., and Gaynor, R.B. 1998. The anti-inflammatory agents aspirin and salicylate inhibit the activity of IкB kinase- $\beta$. Nature. 396:77-80.

9. Yuan, M., et al. 2001. Reversal of obesity- and diet-induced insulin resistance with salicylates or targeted disruption of IKK $\beta$. Science. 293:1673-1677.

10. Kim, J., et al. 2001. Prevention of fat-induced insulin resistance by salicylate. J. Clin. Invest. 108:437-446. doi:10.1172/JCI200111559.

11. Ebstein, W. 1877. Zur therapie des diabetes mellitus, insbesondere uber die anwendung des salicylsauren natron bei demselben. Berliner Klinische Wochenschrift. 24:337-340.

12. Williamson, R.T., and Lond, M.D. 1901. On the treatment of glycosuria and diabetes mellitus with sodium salicylate. Brit. Med. J. 1:760-762.
13. Reid, J., MacDougall, A.I., and Andrews, M.M. 1957. Aspirin and diabetes mellitus. Brit. Med. J. 2:1071-1074.

14. Reid, J., and Lightbody, T.D. 1959. The insulin equivalence of salicylate. Brit. Med. J. 1:897-900.

15. Gilgore, S.G. 1960. The influence of salicylate on hyperglycemia. Dia betes. 9:392-393.

16. Gross, M., and Greenberg, L. 1948. The salicylates. Hillhouse Press. New Haven, Connecticut, USA. 108 PP

17. Newman, W.P., and Brodows, R.G. 1983. Aspirin causes tissue insensitivity to insulin in normal man. J. Clin. Endocrinol. Metab. 57:1102-1106.

18. Giugliano, D., Sacca, L., Scognamiglio, G., Ungaro, B., and Torella, R. 1982. Influence of acetylsalicylic acid on glucose turnover in normal man. Diabete Metab. 8:279-282.

19. Bratusch-Marrain, P.R., Vierhapper, H., Komjati, M., and Waldhausl, W.K. 1985. Acetyl-salicylic impairs insulin-mediated glucose utilization and reduces insulin clearance in healthy and non-insulin-dependent diabetic man. Diabetologia. 28:671-676.

20. Maggs, D.G., et al. 1998. The metabolic effects of troglitazone in noninsulin dependent diabetes: a randomized double-blind, placebo controlled trial. Ann. Int. Med. 128:176-185.

21. Shulman, G.I., et al. 1990. Quantitation of muscle glycogen synthesis in normal subjects and subjects with non-insulin-dependent diabetes by ${ }^{13} \mathrm{C}$ nuclear magnetic resonance spectroscopy. N. Engl. J. Med. 322:223-228.

22. Miles, J., Glasscock, R., Aikens, J., Gerich, J., and Haymond, M. 1983. A microfluorometric method for the determination of free fatty acids in plasma. J. Lipid Res. 24:96-99.

23. Hohorst, H.J. 1965. L-(+)- lactate determination with lactic dehydrogenase. In Methods of enzymatic analysis. H.U. Bergmeyer, editor. Verlag Chemie. Basel, Switzerland. 266-270.

24. Shulman, G.I., et al. 1990. Quantitative comparison of pathways of hepatic glycogen repletion in fed and fasted humans. Am. J. Physiol. 259:E335-E341.

25. Inzucchi, S.E., et al. 1998. Efficacy and metabolic effects of metformin and troglitazone in type 2 diabetes mellitus. N. Engl. J. Med. 338:867-872.

26. Hundal, R.S., et al. 2000. Mechanism by which metformin reduces glucose production in type 2 diabetes. Diabetes. 49:2063-2069.

27. Boden, G. 1997. Role of fatty acids in the pathogenesis of insulin resistance and NIDDM. Diabetes. 46:3-10.

28. Roden, M., et al. 1996. Mechanism of free fatty acid-induced insulin resistance in humans. J. Clin. Invest. 97:2859-2865.

29. Roden, M., et al. 2000. Effects of free fatty acid elevation on postabsorptive endogenous glucose production and gluconeogenesis in man. Diabetes. 49:701-707. 